\title{
Racial Segregation, Income Inequality, and Mortality in US Metropolitan Areas
}

\author{
Amani M. Nuru-Jeter and Thomas A. LaVeist
}

\begin{abstract}
Evidence of the association between income inequality and mortality has been mixed. Studies indicate that growing income inequalities reflect inequalities between, rather than within, racial groups. Racial segregation may play a role. We examine the role of racial segregation on the relationship between income inequality and mortality in a cross-section of US metropolitan areas. Metropolitan areas were included if they had a population of at least 100,000 and were at least $10 \%$ black (N= 107). Deaths for the time period 1991-1999 were used to calculate age-adjusted allcause mortality rates for each metropolitan statistical area (MSA) using direct ageadjustment techniques. Multivariate least squares regression was used to examine associations for the total sample and for blacks and whites separately. Income inequality was associated with lower mortality rates among whites and higher mortality rates among blacks. There was a significant interaction between income inequality and racial segregation. A significant graded inverse income inequality/mortality association was found for MSAs with higher versus lower levels of black-white racial segregation. Effects were stronger among whites than among blacks. A positive income inequality/ mortality association was found in MSAs with higher versus lower levels of Hispanicwhite segregation. Uncertainty regarding the income inequality/mortality association found in previous studies may be related to the omission of important variables such as racial segregation that modify associations differently between groups. Research is needed to further elucidate the risk and protective effects of racial segregation across groups.
\end{abstract}

KEYWORDS Income distribution, Segregation, Racelethnicity, Mortality

\section{INTRODUCTION}

Evidence of the relationship between income inequality and mortality in the United States has been mixed. The majority of the published research shows a positive income inequality/mortality association. ${ }^{1-15}$ However, there is also evidence suggesting that the association between income inequality and mortality is conditional on other factors such as racial density, ${ }^{16-20}$. Further, income inequality in the United States largely reflects income inequality between racial groups as the bifurcation of the middle class. There is suggestion that this, along with racial residential segregation, has resulted in racial differences in the concentration of poverty and affluence with blacks experiencing higher levels of concentrated poverty compared to whites. ${ }^{17,21-23}$ This

Nuru-Jeter is with the Divisions of Community Health and Human Development, and Epidemiology, School of Public Health, University of California Berkeley, Berkeley, CA, USA; LaVeist is with the Department of Health Policy and Management, Bloomberg School of Public Health, Johns Hopkins University, Baltimore, MD, USA.

Correspondence: Amani M. Nuru-Jeter, Divisions of Community Health and Human Development, and Epidemiology, School of Public Health, University of California Berkeley, Berkeley, CA, USA. (E-mail: anjeter@berkeley.edu) 
has to do both with existing patterns of racial segregation and the higher proportion of low-income blacks relative to low-income whites.

In spite of this phenomenon, little has been done to examine how the income inequality/mortality relationship varies as a function of race, racial density, or racial segregation. Some studies have adjusted for \% black, but results have been mixed. Whereas some sudies show a significant positive association between income inequality and mortality after adjusting for \% black, others show that after adjusting for \% black, income inequality is no longer significantly associated with mortality. Still others show a protective effect of income inequality after adjusting for \% black. ${ }^{17,24-29}$ Income inequality and mortality are both higher among blacks than among whites, ${ }^{11,19,30}$ and income inequality is also related to growing spatial separation between blacks and whites. ${ }^{17,22,23}$ However, it is unclear whether and to what extent racial segregation impacts the association between income inequality and mortality. Understanding these associations may help elucidate the mechanisms driving the association between income inequality and mortality both between and within racial groups in the United States.

We investigate the role of racial residential segregation on the relationship between income inequality and mortality in US metropolitan areas. Specifically, we examine whether income inequality remains a significant predictor of mortality after adjusting for racial residential segregation, and whether racial segregation modifies the association between income inequality and mortality. Although black-white segregation is of primary interest given previous studies indicating the degree of hypersegregation among blacks, ${ }^{31}$ demographic trends from 1980 to 2000 indicate that the modest decline in segregation among blacks is not related to their integration with whites, but to the in-migration of other racial minority groups who are also segregated from whites, particularly Hispanics. ${ }^{32}$ Therefore, we also examine the role of Hispanic segregation from whites on the income inequality/ mortality relation.

\section{METHODS}

\section{Data Source and Study Sample}

We examined a cross-section of 107 metropolitan areas in the United States. Metropolitan statistical areas (MSAs) consist of a core urban area-a cluster of contiguous census blocks, each with a population of at least 1,000 persons per square mile, surrounded by census block groups with a population of at least 500 persons per square mile-with a population of at least 50,000 and the surrounding counties that share social and economic ties (i.e., interaction of people and activities among places) to the urban core based on standards for commuter flow (i.e., \% commuting). ${ }^{33,34}$ For the present study, MSAs were included if: (1) they had a population of at least 100,000 , in order to match the mortality file data; and (2) they had a population that was at least $10 \%$ non-Hispanic black, a common standard used for calculating stable race-specific estimates. ${ }^{16,35,36}$ In 1990, there were 288 MSAs with a population of at least 100,000; 107 of these were at least $10 \%$ non-Hispanic black.

\section{Measures}

The Multiple Cause of Death Public Use data file provides a record of all deaths occurring annually in the United States. Deaths for the time period 1991-1999 were linked to yearly population counts custom tabulated by the National Center for 
Health Statistics ${ }^{37}$ and used to calculate age-adjusted all-cause mortality rates per 100,000 population for each MSA using direct age-adjustment techniques (1999 standard population). Mortality data were combined into 3-year data pools in order to stabilize mortality estimates: ${ }^{19,26} 1991-1993,1994-1996$, and 1997-1999. Mortality rates were calculated for the total population and for non-Hispanic blacks and non-Hispanic whites separately (hereafter blacks and whites, respectively).

The 1990 Gini coefficient was used to measure income inequality. The Gini coefficient is the most commonly used indicator of income inequality. The Gini was tabulated using detailed income data from the Income Statistics Branch of the Housing and Household Economic Statistics Division of the Census Bureau. The derivation of the Gini coefficient has been described in detail elsewhere. ${ }^{7}$ Briefly, it measures how much the income distribution for a given geographic area deviates from what would be an even distribution for that area. For example, if income were evenly distributed, each successive tenth percentile of the population would hold $10 \%$ of the income in the area. The Gini increases when any given tenth of the population holds a disproportionate share of the income, either less than or more than a $10 \%$ share of the income. The Gini coefficient ranges from 0 to 1 with higher scores reflecting greater income inequality.

Racial segregation data are from the Mumford Center for Comparative Urban and Regional Research. Racial segregation was measured using the 1990 Dissimilarity Index (Dx). The Dx measures the degree to which racial groups are evenly distributed across areal units. The $\mathrm{Dx}$ is derived by plotting the cumulative proportion of a given racial minority group against the cumulative proportion of a given majority group across areal units. ${ }^{38}$ The $\mathrm{Dx}$ is the most commonly used measure of racial residential segregation. Conceptually, the Dx measures the proportion of a given racial minority group that would have to move in order to achieve an even or proportionate distribution of racial groups across areal units (e.g., census tracts) relative to average proportion of that group for a given higher unit of aggregation (e.g., MSA). The Dx ranges from 0 to 1 . Higher scores reflect higher levels of racial segregation.

We examined whether the $\mathrm{Dx}$ modifies the association between income inequality and mortality. To facilitate interpretation, the Dx was recoded into a categorical variable. Black-white segregation was defined as low $(\geq 1$ standard deviation (SD) below the median), medium $(<1 \mathrm{SD}$ below the median to $<1 \mathrm{SD}$ above the median), and high ( $\geq 1$ SD above the median). Only two MSAs fell in the low segregation category for Hispanic-white segregation. Therefore, to achieve a more even distribution, Hispanic-white segregation was recoded using the interquartile range: $\leq 25$ th percentile, $>25$ th and $<75$ th percentile, and $\geq 75$ th percentile.

Covariate data were compiled using Summary Tape File 3C from the 1990 US Decennial Census, which contains sample population and housing data that have been weighted to represent the total US population. Data collected from this file include: median household income, total population, \% males, \% unemployment, $\%$ black, \% white, \% Hispanic, and region of the country. Region of the country was specified as a categorical variable indicating 4 regions: northeast, midwest, south, and west.

\section{Analysis}

Correlation statistics were used to examine correlations between study variables and assess colinearity. Multivariate ordinary least squares regression was used to 
examine the association between income inequality and mortality rate. We first assessed the income inequality/mortality association. Next, we examined whether black-white segregation was a significant effect modifier of the income inequality/ mortality relation and, finally, whether Hispanic-white segregation modified the income inequality/mortality relation. All models included adjustment for median household income, total population, \% black, and \% Hispanic. Percent unemployed, \% males, region of the country, and Hispanic segregation (HDx) were included where significant at $p<0.05$. The a priori inclusion of certain and not other control variables was based on the current literature regarding factors known to confound the income inequality/mortality relationship. Factors that were more exploratory in nature were only included when significant at $p \leq 0.05$. The natural $\log$ transformation of total population was used to weight for different population sizes and account for nonnormality in the data. Multivariate colinearity was assessed using variance inflation factors and was not a hindrance in the data. Analyses were run for the total population and for blacks and whites separately. Statistical analyses were performed using Intercooled Stata version 9.0. ${ }^{39}$

\section{RESULTS}

\section{Sample Characteristics}

Sample characteristics are shown in Table 1. The sample mean level of income inequality is 0.44 , a relatively high level of income inequality, ${ }^{8}$ with blacks having higher than average levels (0.46) and whites having lower than average levels (0.42). The mean level of black-white residential segregation was also relatively high at $0.60 .^{31}$ This means that, on average, $60 \%$ of blacks would have to move in order to achieve an even (or proportionate) distribution of blacks and whites across census tracts compared to their respective proportions for the MSA. Black-white segregation ranges from 0.23 to 0.90 across MSAs. The mean level of segregation for Hispanics is 0.34 ranging from 0.13 to 0.68 . Blacks and whites comprise $20 \%$ and $73 \%$ of the study sample, respectively. The sample mean household income is

TABLE 1 Sample characteristics of selected MSAs in the United States $(\geq 100,000$ population and $\geq 10 \%$ black; 1990, $N=107$ )

\begin{tabular}{lllll}
\hline Variable & Mean & SD & Min & Max \\
\hline $\begin{array}{l}\text { Income inequality (Gini) } \\
\text { Total }\end{array}$ & 0.44 & & & \\
White & 0.42 & 0.03 & 0.37 & 0.51 \\
Black & 0.46 & 0.03 & 0.37 & 0.51 \\
Racial segregation (Dx) & & & 0.35 & 0.53 \\
Black-white & 0.60 & 0.14 & & \\
Hispanic-white & 0.34 & 0.13 & 0.23 & 0.90 \\
\% White & 73.00 & 10.47 & 0.14 & 0.68 \\
\% Black & 20.10 & 8.33 & 30.36 & 87.22 \\
\% Hispanic & 4.78 & 7.51 & 9.97 & 45.50 \\
Median income & $28,982.86$ & $5,362.83$ & 0.28 & 49.03 \\
Total population (In) & $1,006,781$ & $1,549,373$ & $108,411.00$ & $46,884.00$ \\
\% Males & 48.56 & 1.52 & 46.99 & $8,862,948$ \\
\% Unemployed & 6.25 & 1.49 & 3.15 & 59.64 \\
\hline
\end{tabular}


approximately $\$ 28,982$. The sample is $49 \%$ men, and the average rate of unemployment is $6.25 \%$.

\section{Multivariate Analysis}

Results of the multivariate regression analyses are presented in Tables 2, 3, and 4. We present the data for the 1994-1996 time period only. Estimates for the 19971999 time period are also significant. For simplicity, we present the data for only 1 of the 2 period,s choosing the more conservative of the 2 . Table 2 presents the results for the full study sample (i.e., all racial groups combined). Percent unemployed did not have a significant effect on the study results and was therefore excluded from the final models. We omitted observations greater than 1.5 standard deviations beyond the interquartile range to account for multivariate outliers, which was less than $7 \%$ of the study sample. ${ }^{40}$

Table 2 shows an inverse income inequality/mortality relation such that higher income inequality is associated with lower mortality rates. This finding is robust to controls for \% black, \% Hispanic, and region of the country (model 2). Black-white racial segregation is a significant modifier of this association fully accounting for the previously observed independent association between income inequality and

TABLE 2 Adjusted regression coefficients for mortality rate per 100,000 population (19941996) regressed on income inequality (1990) in selected US metropolitan areas

\begin{tabular}{|c|c|c|c|c|}
\hline Predictor variable & Model 1 & Model 2 & Model 3 & Model 4 \\
\hline Gini coefficient & $-790.22^{* * * * *}$ & $-621.47 * * * *$ & -90.42 & -288.95 \\
\hline Median income & $-0.01^{* * * *}$ & $-0.00 * * * *$ & $-0.00 * * * *$ & $-0.00 * * * *$ \\
\hline In total population & 0.00 & 0.00 & $0.00 * *$ & $0.00 * *$ \\
\hline$\%$ Males & $-15.94^{* * * * *}$ & $-12.02^{* * * *}$ & $-9.02^{* * * *}$ & $-9.63 * * * *$ \\
\hline$\%$ Black & & $1.03^{* * *}$ & $1.13^{* * *}$ & $1.18^{* * *}$ \\
\hline$\%$ Hispanic & & $-1.05^{* * *}$ & $-1.11^{* *}$ & $-1.58^{* * *}$ \\
\hline \multicolumn{5}{|c|}{ Region of the country } \\
\hline South & & $-22.04 * *$ & $-30.78^{* * *}$ & $-25.75^{* *}$ \\
\hline Midwest & & -11.85 & -14.56 & -8.87 \\
\hline West & & -27.96 & $-45.56^{* *}$ & $-45.05^{* *}$ \\
\hline \multicolumn{5}{|c|}{ Black-white segregation (BDx) } \\
\hline BDx mid & & & $271.07^{*}$ & $358.85^{* *}$ \\
\hline BDx high & & & $385.73^{* *}$ & $517.48^{* * *}$ \\
\hline \multicolumn{5}{|c|}{ Hispanic-white segregation (HDx) } \\
\hline HDx mid & & & & $-254.30^{* *}$ \\
\hline HDx high & & & & -258.39 \\
\hline \multicolumn{5}{|l|}{ Interactions } \\
\hline Gini*BDx mid & & & $-608.22^{*}$ & $-803.17^{* * *}$ \\
\hline Gini*BDx high & & & $-903.80^{* *}$ & $-1208.69 * *$ \\
\hline Gini*HDx mid & & & & $560.15^{* * *}$ \\
\hline Gini*HDx high & & & & 601.46 \\
\hline Adjusted $R^{2}$ & 0.46 & 0.54 & 0.56 & 0.57 \\
\hline
\end{tabular}

$B D x$ mid intermediate black-white segregation (where $D x=0.47-0.74), B D x$ high highest black-white segregation (where $\mathrm{Dx}>0.74$ ); reference is lowest black-white segregation where $\mathrm{Dx}<0.47$

HDx mid intermediate Hispanic-white segregation (where $D x=0.18-0.43$ ), HDx high highest Hispanic-white segregation (where $\mathrm{Dx}>0.43$ ); reference is lowest Hispanic-white segregation, where $\mathrm{Dx}<0.18$ Reference for region of the country is northeast. $N=104$ ${ }^{*} p<0.10,{ }^{* *} p<0.05,{ }^{* * *} p<0.01,{ }^{* * * *} p<0.001$ 
TABLE 3 Adjusted regression coefficients for mortality rate per 100,000 population (19941996) regressed on income inequality (1990) among blacks in selected US metropolitan areas

\begin{tabular}{lccc}
\hline Predictor variable & Model 1 & Model 2 & Model 3 \\
\hline Gini coefficient & $28.82^{* *}$ & $34.95^{* * * *}$ & $68.23^{* * *}$ \\
Median income & 0.00 & $0.00^{* * * *}$ & 0.00 \\
In total population & 0.00 & -0.00 & -0.00 \\
\% Black & & $0.15^{* * * *}$ & $0.16^{* * *}$ \\
\% Hispanic & & $0.16^{* * *}$ & $0.18^{* * *}$ \\
Black-white segregation (BDx) & & & $32.34^{* * *}$ \\
BDx mid & & & $49.10^{* * *}$ \\
BDx high & & & $-67.24^{* * *}$ \\
Interactions & & & $-98.52^{* * *}$ \\
Gini*BDx mid & & 0.13 \\
Gini*BDx high & 0.05 & & 0.18 \\
Adjusted $R^{2}$ & & & \\
\hline
\end{tabular}

$B D x$ mid intermediate black segregation where $\mathrm{Dx}=0.47-0.74, B D x$ high highest black segregation where $\mathrm{Dx}>0.74$; reference is lowest black segregation where $\mathrm{Dx}<0.47$

$N=104$

${ }^{*} p<0.10,{ }^{* *} p<0.05,{ }^{* * *} p<0.01, * * * * p<0.001$

TABLE 4 Adjusted regression coefficients for mortality rates per 100,000 population (19941996) regressed on income inequality (1990) among whites in selected US metropolitan areas

\begin{tabular}{|c|c|c|c|c|}
\hline Predictor variable & Model 1 & Model 2 & Model 3 & Model 4 \\
\hline Gini coefficient & $-478.04 * * * *$ & $-406.63 * * *$ & 90.77 & -74.44 \\
\hline Median income & $-0.00 * * * *$ & $-0.00 * * * *$ & $-0.00 * * * *$ & $-0.00 * * * *$ \\
\hline In total population & $0.00 * *$ & $0.00 *$ & $0.00 * * *$ & $0.00 * *$ \\
\hline$\%$ Males & $-7.73 * * * *$ & $-6.31 * * *$ & $-4.53^{* *}$ & $-4.63 * *$ \\
\hline$\%$ Black & & 0.53 & $0.64 *$ & $0.68^{* *}$ \\
\hline \% Hispanic & & -0.53 & -0.55 & $-1.57^{* *}$ \\
\hline \multicolumn{5}{|c|}{ Region of the country } \\
\hline South & & $-30.75 * * *$ & $-38.55^{* * * *}$ & $-22.62 * *$ \\
\hline Midwest & & $-18.92^{*}$ & -17.11 & -2.63 \\
\hline West & & 6.68 & -7.93 & 11.61 \\
\hline \multicolumn{5}{|c|}{ Black-white segregation (BDx) } \\
\hline BDx mid & & & $220.83^{*}$ & $266.67 * *$ \\
\hline BDx high & & & $262.03^{*}$ & $336.67 * *$ \\
\hline \multicolumn{5}{|c|}{ Hispanic-white segregation (HDx) } \\
\hline HDx mid & & & & -166.36 \\
\hline HDx high & & & & $-250.29 *$ \\
\hline Gini*BDx mid & & & $-530.92^{*}$ & $-635.23 * *$ \\
\hline Gini*BDx high & & & $-666.63^{* *}$ & $-846.56^{* *}$ \\
\hline Gini*HDx mid & & & & 374.27 \\
\hline Gini*HDx high & & & & $630.73 *$ \\
\hline Adjusted $R^{2}$ & 0.29 & 0.35 & 0.38 & 0.42 \\
\hline
\end{tabular}

$B D x$ mid intermediate black segregation where $\mathrm{Dx}=0.47-0.74, B D x$ high highest black segregation where $\mathrm{Dx}$ $>0.74$; reference is lowest black segregation where $\mathrm{Dx}<0.47$

$H D x$ mid intermediate Hispanic-white segregation where $D x=0.18-0.43, H D x$ high highest Hispanic segregation where $\mathrm{Dx}>0.43$; reference is lowest Hispanic segregation where $\mathrm{Dx}<0.18$

Reference for region of the country is northeast. $N=100$

${ }^{*} p<0.10,{ }^{* *} p<0.05,{ }^{* * *} p<0.01,{ }^{* * * *} p<0.001$ 
mortality (model 3). The inverse association between income inequality and mortality is stronger in MSAs with higher versus lower levels of black-white residential segregation. Compared to MSAs with the lowest levels of black racial segregation ( $\mathrm{Dx} \leq 0.47)$, a 1 -unit increase in income inequality $(0.01)$ is associated with roughly 600 fewer deaths per 100,000 population $(p<0.10)$ in MSAs with intermediate levels of black racial segregation $(\mathrm{Dx}=0.47-0.74)$, and approximately 900 fewer deaths per 100,000 population $(p<0.05)$ in MSAs with the highest levels of black racial segregation ( $\mathrm{Dx}>0.74)$.

Hispanic segregation is also an effect modifier of the income inequality/mortality relation. Higher income inequality is associated with higher mortality rates in MSAs with higher versus lower levels of Hispanic segregation. Compared to MSAs with the lowest levels of Hispanic segregation $(\mathrm{Dx} \leq 0.18)$, a 1-unit increase in the Gini is associated with 560 more deaths per 100,000 population $(p<0.05)$ in MSAs with intermediate levels of Hispanic segregation $(\mathrm{Dx}=0.18-0.43)$. The interaction of both black and Hispanic segregation with income inequality is robust to controls for $\%$ black and \% Hispanic, 2 important covariates given that the derivation of the Dx does not account for the relative proportions of each racial group.

Table 3 displays regression estimates for blacks. Among blacks, income inequality is a significant positive predictor of mortality (models 1 and 2). However, black-white racial segregation modifies that association (model 3) buffering the negative effect of income inequality among blacks. Higher income inequality is associated with lower mortality in MSAs with higher versus lower levels of black racial segregation. Percent unemployed, \% males, region of the country, and Hispanic segregation did not significantly predict mortality among blacks and did not change the other model estimates, and therefore were excluded from the final models.

Results for whites are shown in Table 4. There is a strong significant inverse association between income inequality and mortality among whites $(p<0.001)$. Black racial segregation also modifies the income inequality/mortality relation among whites. Higher income inequality is associated with lower mortality rates in MSAs with higher versus lower levels of black racial segregation $(p<0.05)$. On the contrary, higher income inequality is associated with higher mortality rates in MSAs with higher versus lower levels of Hispanic segregation $(p<0.10)$.

\section{DISCUSSION}

Our findings support previous research showing a protective effect of income inequality on mortality once \% black is accounted for. We also found a protective effect of income inequality prior to adjusting for \% black, which may have to do with the dynamics between income inequality and mortality in areas with a higher density of blacks. We included only those MSAs that were at least $10 \%$ black. Our study sample was $72 \%$ white. The increase in income inequality in the United States largely reflects income inequalities between affluent whites and poor blacks. Therefore, findings for the full sample may reflect the net gain in health experienced by affluent whites.

Consistent with other literature, there was a significant positive association between both \% black and black racial segregation and mortality. ${ }^{16}$ Hispanic segregation and \% Hispanic, on the other hand, showed an inverse association with mortality rates, consistent with previous evidence demonstrating the protective effects of social support and coethnic ties among Hispanics. ${ }^{30,41-45}$ 
The results show that racial segregation modifies the income inequality/ mortality association. In the full sample, the inverse association between income inequality and mortality was greater in MSAs with higher versus lower levels of black racial segregation. The same was found among whites. Among blacks, there was a positive association between income inequality and mortality prior to the inclusion of the interaction term, after which the same graded inverse association between income inequality and mortality was found with increasing levels of black racial segregation. The strength of the inverse association, however, differed greatly between the 2 groups. Compared to the full sample, the protective effect of income inequality by levels of racial segregation was attenuated by roughly $25 \%$ among whites and $90 \%$ among blacks, suggesting that the harmful effects of racial segregation are more pronounced among blacks than among whites. In their study of 107 US cities with at least $10 \%$ black population, Collins and Williams also found the harmful effects of racial segregation on health to be greater among blacks than among whites. ${ }^{36}$

Metropolitan areas with the highest \% of blacks and the highest degree of black-white racial residential segregation have the smallest ratio of city-to-suburban jobs per person, city family median income to suburban family median income, city to suburban total housing units, and suburban to city unemployment. ${ }^{21}$ Importantly, racial segregation has been positively associated with higher poverty and lower status occupations among blacks though not among whites, suggesting that racial segregation may concentrate social and material disadvantage, particularly among blacks. ${ }^{36,46,47}$ Racially segregated areas, particularly lower income areas, have been associated with lower quality schools, fewer employment and economic opportunities, exposure to crime, substandard housing, exposure to toxins and pollutants, and isolation from broader social networks, ${ }^{48,49}$ all of which have been associated with poorer health. We found a positive association between black-white racial segregation and mortality in the full sample and in race-specific models showing that racial segregation is independently associated with poorer health for all groups.

The protective effect of income inequality in areas with higher versus lower levels of racial segregation may reflect the protective effects of racial segregation. Previous work shows that black racially segregated areas have higher levels of black political empowerment and better investment in municipal services such as sewage, fire, and street services and social services such as social welfare, health, and protective services. ${ }^{35,48}$ Racial segregation has also been associated with higher levels of group social cohesion, ${ }^{50}$ which in turn is inversely associated with mortality. ${ }^{3}$

Although income inequality concentrates poverty among blacks and results in lower resource communities for both middle- and upper-income blacks, the protective effects of income inequality among blacks in areas with higher versus lower levels of black-white racial segregation are likely a reflection of high levels of social cohesion. Evidence suggests that the congruence of living around similar others is protective of health. One study found a significant positive gradient relation between income incongruence and mortality with higher mortality rates among lowincome persons living in higher versus lower income neighborhoods. ${ }^{51}$ These findings suggest that the material disadvantages associated with low-income areas may be outweighed by the social advantages associated with social cohesion, collective efficacy, and group solidarity. ${ }^{30,41,42,50}$ Similarly, the stigma associated with being in the minority may confer health risks that outweigh the material advantages of higher income neighborhoods. Further research is needed to better 
understand the dynamics between risk factors and resilience factors in predicting mortality among blacks.

The protective effects of income inequality among whites may reflect more affluent living conditions due to the concentration of affluence among whites. MSAs with high levels of concentrated affluence and poverty also have high levels of black-white racial segregation, ${ }^{21}$ and increasing income inequality is associated with the concentration of poverty and affluence for blacks and whites, respectively.

Hispanic racial segregation also modifies the income inequality/mortality relation. There was a significant positive income inequality/mortality association in areas with higher versus lower levels of Hispanic racial segregation. This may also have to do with the concentration of poverty. However, previous work indicates that the protective effects of group density may outweigh the negative impact of low social status. Our sample of MSAs had an average of $5 \%$ Hispanics. Further research with a higher percentage of Hispanics is needed to better understand the factors associated with this finding.

Several factors should be considered in interpreting the study results. This crosssectional ecological study does not draw causal inferences but rather highlights some of the place-level factors relevant for understanding racial differences in the income inequality/mortality relation. We examined 107 US metropolitan areas with a population of at least 100,000 and at least $10 \%$ black. Our findings are, therefore, representative of those MSAs. Further research is needed to distinguish between the dynamics of income inequality and racial segregation in areas with a lower versus higher density of blacks.

We chose the Dx as our measure of segregation. The Dx has many strengths including its common usage, which makes the results of our study comparable to many others. The Dx is also easy to compute, especially when comparing the distribution of 2 groups. When the number of groups exceeds 2 , which would be the case when examining segregation between multiple ethnic groups, other measures of segregation, such as the Theil Index, the Multiethnic Entropy Index, and White's Index of Spatial Proximity, have been found to be less cumbersome and less prone to error. $^{38,52-55}$ Our results likely underestimate the degree of black and Hispanic racial segregation, possibly resulting in more conservative associations. We estimated the segregation of blacks and Hispanics from whites, which does not account for their segregation from other groups. Blacks are the most racially segregated group in the United States, followed by Hispanics. ${ }^{31,56}$ Whereas some studies suggest that black racial segregation is lower in areas with high multiethnic concentrations, that may depend on the degree of black racial concentration and clustering. ${ }^{31,54,57,58}$ Understanding how the levels of racial segregation for blacks change when looking at segregation from, or level of interaction with, other groups, versus whites alone-and how much of the association between racial segregation and mortality is attributable to the segregation of blacks from whites versus blacks from non-blacks-would inform the types of strategies most useful for improving health, and perhaps give a more accurate assessment of the degree of black racial segregation. ${ }^{53}$ For Hispanics, one might consider the difference between Mexican versus non-Mexican, Puerto Rican versus non-Puerto Rican, etc., rather than combining these distinct ethnicities into one panethnicity. We did not have access to data at that level of specificity. However, a multiethnic framework including consideration of other racial minority groups is warranted given the increasing levels of racial and ethnic diversity in the United States. Additionally, accounting for the multidimensional nature of racial segregation would be helpful in this regard. 
We used the Gini to measure income inequality. One of the limitations of the Gini is that it is not sensitive to spatial redistributions of income among areas either above or below the proportionate distribution of income across areal units, commonly referred to as the transfer principle. ${ }^{38,52}$ The Gini also is not sensitive to the shape of the income distribution and is therefore not able to distinguish between 2 MSAs with the same value of income inequality but different income distributions. Despite these limitations, the Gini is highly correlated with other measures of income inequality and is similar to other measures in its association with mortality. ${ }^{3}$ Finally, income inequality and racial segregation data are from 1990. Mortality data are also from the 1990s. Importantly, levels of income inequality $^{59}$ and racial segregation ${ }^{32}$ remained relatively stable for the time period 1990 to 2000, and black-white differences in mortality did not change appreciably during the 1990-2000 time period. ${ }^{60}$ Future studies examining the stability of these associations over time are warranted.

To our knowledge, this is only the second study to examine explicitly the role of racial residential segregation in the income inequality/mortality relationship, ${ }^{16}$ and the first to examine the potential moderating role of racial segregation, and to examine these associations in a sample of MSAs with a higher concentration of blacks (i.e., $\geq 10 \%$ ). Previous work shows that the income inequality/mortality relation varies with the degree of black racial concentration. In their study of US counties, McLaughlin and Stokes found a positive income inequality/mortality association in areas with a low concentration of blacks. ${ }^{19}$ As \% black increased, the nature of the relationship between income inequality and mortality changed such that higher inequality was associated with lower mortality, consistent with our study findings. Our finding of a positive association between black racial segregation and mortality and of an inverse income inequality/mortality association by degree of racial segregation may reflect dynamics unique to geographic areas with a higher concentration of blacks. It is curious that region of the country was more relevant in the full sample than in either of the race-specific groups, given both the historical and contemporary differences between regions both in levels of racial segregation and mortality. It is possible that mortality differences by region are more related to the cultural aspects of place than to cultural and other differences between racial groups in those places. Other outcomes have similarly shown strong regional variations that cut across racial groups. ${ }^{61}$ Future research is needed to further explore these associations.

Given the mixed evidence, there continues to be some debate about whether studying the health effects of income inequality is a worthwhile pursuit. However, some of that uncertainty may be related to the omission of important variables such as racial segregation that modify associations differently for different groups. Mixed methods approaches may help in further exploring the social realities of racial segregation for different groups. Qualitative methods such as focus groups and key informant interviews, as well as area-based audits capturing the social, economic, and physical trends of places over time, would be particularly illuminating. Additionally, examination of cause-specific morbidities and mortalities may help inform the mechanisms through which income inequality impacts health differently for different racial groups. Understanding the dynamics of income inequality, racial segregation, and mortality for other groups, particularly Hispanic groups given their growing representation in the US population, would also inform the ways in which these associations vary across groups. Another important direction for future research is examining the interaction between racial segregation and socioeconomic status (SES) among minority 
group members. Specifically, whether SES modifies the association of racial segregation and mortality among minority group members and whether that interaction modifies the association between income inequality and mortality.

In summary, our finding that racial segregation does not operate the same across groups highlights the social aspects of place that matter over and above material resources and calls attention to the need to further examine both the social and economic correlates of racial segregation and how those factors affect groups differently.

OPEN ACCESS This article is distributed under the terms of the Creative Commons Attribution Noncommercial License which permits any noncommercial use, distribution, and reproduction in any medium, provided the original author(s) and source are credited.

\section{REFERENCES}

1. Kaplan GA, Pamuk ER, Lynch JW, Cohen RD, Balfour JL. Inequality in income and mortality in the United States: analysis of mortality and potential pathways. BMJ. 1996; 312(7037): 999-1003.

2. Wilkinson RG. Socioeconomic determinants of health. Health inequalities: relative or absolute material standards? BMJ. 1997; 314(7080): 591-5.

3. Kawachi I, Kennedy BP. The relationship of income inequality to mortality: does the choice of indicator matter? Soc Sci Med. 1997; 45(7): 1121-7.

4. Kawachi I, Kennedy BP, Lochner K, Prothrow-Stith D. Social capital, income inequality, and mortality. Am J Public Health. 1997; 87(9): 1491-8.

5. Kennedy BP, Kawachi I, Prothrow-Stith D. Income distribution and mortality: cross sectional ecological study of the Robin Hood index in the United States. BMJ. 1996; 312 (7037): 1004-7.

6. Lobmayer P, Wilkinson RG. Inequality, residential segregation by income, and mortality in US cities. J Epidemiol Community Health. 2002; 56(3): 183-7.

7. Lynch JW, Kaplan GA, Pamuk ER, et al. Income inequality and mortality in metropolitan areas of the United States. Am J Public Health. 1998; 88(7): 1074-80.

8. Lynch JW, Smith GD, Kaplan GA, House JS. Income inequality and mortality: importance to health of individual income, psychosocial environment, or material conditions. BMJ. 2000; 320(7243): 1200-4.

9. Muller A. Education, income inequality, and mortality: a multiple regression analysis. BMJ. 2002; 324(7328): 23-5.

10. Ronzio CR. Urban premature mortality in the U.S. between 1980 and 1990: changing roles of income inequality and social spending. J Public Health Policy. 2003; 24(3-4): 386-400.

11. Ronzio CR, Pamuk E, Squires GD. The politics of preventable deaths: local spending, income inequality, and premature mortality in US cities. J Epidemiol Community Health. 2004; 58(3): 175-9.

12. Waldmann RJ. Income distribution and infant mortality. Q J Econ. 1992; 107(4): 1283-302.

13. Wilkinson RG. Income distribution and life expectancy. Br Med J. 1992; 304: 165-8.

14. Wilkinson RG. Unhealthy societies: the afflictions of inequality. Longon: Routledge; 1996.

15. Wolfson W, Kaplan G, Lynch J, Ross N, Backlund E. Relation between income inequality and mortality: empirical demonstration. Br Med J. 1999; 319(7215): 953-5.

16. Cooper RS, Kennelly JF, Durazo-Arvizu R, Oh HJ, Kaplan G, Lynch J. Relationship between premature mortality and socioeconomic factors in Black and White populations of US metropolitan areas. Public Health Rep. 2001; 116(5): 464-73. 
17. Deaton A, Lubotsky D. Mortality, inequality and race in American cities and states. Soc Sci Med. 2003; 56(6): 1139-53.

18. LeClere FB, Soobader MJ. The effect of income inequality on the health of selected US demographic groups. Am J Public Health. 2000; 90(12): 1892-7.

19. McLaughlin DK, Stokes CS. Income inequality and mortality in US counties: does minority racial concentration matter? Am J Public Health. 2002; 92(1): 99-104.

20. Mellor JM, Milyo J. Reexamining the evidence of an ecological association between income inequality and health. J Health Polit Policy Law. 2001; 26(3): 487-522.

21. Coulton CJ, Chow J, Wang EC, Su M. Geographic concentration of affluence and poverty in 100 metropolitan areas, 1990. Urban Aff Rev. 1996; 32(2): 186-216.

22. Massey DS, Eggers ML. The ecology of inequality: minorities and the concentration of poverty, 1970-1980. Am J Sociol. 1990; 95(5): 1153-88.

23. Massey DS, Eggers ML. The spatial concentration of affluence and poverty during the 1970s. Urban Aff Q. 1993; 29(2): 299-315.

24. Ash M, Robinson DE. Inequality, race, and mortality in U.S. cities: a political and econometric review of Deaton and Lubotsky (56:6, 1139-1153, 2003). Soc Sci Med. 2009; 68(11): 1909-13.

25. Backlund E, Rowe G, Lynch J, Wolfson MC, Kaplan GA, Sorlie PD. Income inequality and mortality: a multilevel prospective study of 521,248 individuals in 50 US states. Int J Epidemiol. 2007; 36(3): 590-6.

26. Lochner K, Pamuk E, Makuc D, Kennedy BP, Kawachi I. State-level income inequality and individual mortality risk: a prospective, multilevel study. Am J Public Health. 2001; 91(3): 385-91.

27. Miller D, Paxon C. Relative income, race, and mortality. J Health Econ. 2006; 25: 979-1003.

28. Ram R. Income inequality, poverty, and population health: evidence from recent data for the United States. Soc Sci Med. 2005; 61(12): 2568-76.

29. Shi L, Macinko J, Starfield B, Politzer R, Xu J. Primary care, race, and mortality in US states. Soc Sci Med. 2005; 61(1): 65-75.

30. Browning CR, Cagney KA. Neighborhood structural disadvantage, collective efficacy, and self-rated physical health in an urban setting. J Health Soc Behav. 2002; 43(4): 383-99.

31. Massey DS, Denton NA. Hypersegregation in U.S. metropolitan areas: Black and Hispanic segregation along five dimensions. Demography. 1989; 26(3): 373-91.

32. Logan JR, Stults BJ, Farley R. Segregation of minorities in the metropolis: two decades of change. Demography. 2004; 41(1): 1-22.

33. Bureau UC. Geographic area description: metropolitan area cartographic boundary files. https://ask.census.gov/cgi-in/askcensus.cfg/php/enduser/std_adp.php?p_faqid=623\& p_created $=1092150238 \&$ p_sid $=O r \_M E v U j \& p \_$accessibility $=0 \& p \_$redirect $=\&$ p_srch $=1 \&$ p_lva $=\&$ p_sp $=$ cF 9 zcm NoPTEmcF 9 zb 3 J0X2J5PSZwX2 d y a WRzb3J0PSZwX3Jvd19jbnQ9MjQsMjQmcF9wcm9kcz0mcF9jYXRzPSZwX3B2 PSZwX2N2PSZwX3BhZ2U9MSZwX3NlYXJjaF90ZXh0PXVyYmFuaXplZCBhcm Vh\&p_li=\&p_topview=1 Accessed July 10, 2009

34. Federal Register (1998); vol. 63:70526-70562.

35. Laveist TA. Segregation, poverty, and empowerment: health consequences for African Americans. Milbank Q. 1993; 71(1): 41-64.

36. Collins CA, Williams DR. Segregation and mortality: the deadly effects of racism? Sociol Forum. 1999; 14(3): 495-523.

37. Pees M. US Metropolitan Area Yearly Population Counts. Hyattsville, MD: National Center for Health Statistics; Nov 2002.

38. Massey DS, Denton NA. The dimensions of residential segregation. Soc Forces. 1988; 67 (2): 281-315.

39. Intercooled Stata [computer program]. Version Release 9. College Station, TX: Stata Corporation; 2007.

40. Tabachnik BG, Fidell LS. Using multivariate statistics. Boston: Allyn and Bacon; 2001. 
41. Anderson E. The Imperative of Integration. Princeton: Princeton University Press. In press.

42. Pickett KE, Wilkinson RG. People like us: ethnic group density effects on health. Ethn Health. 2008; 13(4): 321-34.

43. Portes A, Fernandez-Kelly P, Haller W. Segmented assimilation on the ground: the new second generation in early adulthood. Ethnic Racial Stud. 2005; 28(6): 1000-40.

44. Eschbach K, Ostir GV, Patel KV, Markides KS, Goodwin JS. Neighborhood context and mortality among older Mexican Americans: is there a barrio advantage? Am J Public Health. 2004; 94(10): 1807-12.

45. Markides KS, Eschbach K. Aging, migration, and mortality: current status of research on the Hispanic paradox. J Gerontol B Psychol Sci Soc Sci. 2005; 60: 68-75. Spec No 2.

46. Massey DS, Fischer MJ. How segregation concentrates poverty. Ethnic Racial Stud. 2000; 23(4): 670-91.

47. Osypuk TL, Galea S, McArdle N, Acevedo-Garcia D. Quantifying separate and unequal: racial and ethnic distributions of neighborhood poverty in metropolitan America. Urban Aff Rev. 2009; 45(1): 25-65.

48. Laveist T. The political empowerment and health status of African-Americans: mapping a new territory. Am J Sociol. 1992; 97(4): 1080-95.

49. Williams DR, Collins C. Racial residential segregation: a fundamental cause of racial disparities in health. Public Health Rep. 2001; 116(5): 404-16.

50. Bledsoe T, Welch S, Sigelman L, Combs M. Residential context and racial solidarity among African Americans. Am J Polit Sci. 1995; 39(2): 434-58.

51. Winkleby M, Cubbin C, Ahn D. Effect of cross-level interaction between individual and neighborhood socioeconomic status on adult mortality rates. Am J Public Health. 2006; 96(12): 2145-53.

52. Iceland J, Weinberg DH, Steinmmetz E. Measurement of Segregation by the U.S. Bureau of the Census in Racial and Ethnic Residential Segregation of the United States: 19802000. Washington, DC: U.S. Census Bureau; 2002.

53. Wong DWS. Measuring multi-ethnic spacial segregation. Urban Geogr. 1998; 19(1): 7787.

54. Iceland J. Talk presented at: American Sociological Association meeting; August 16-19, 2002; Chicago, IL. http://www.census.gov/hhes/www/housing/housing_patterns/pdf/ beyond_black_and_white.pdf. Accessed May 2010. Beyond Black and White: metropolitan residential segregation in multi-ethnic America: US Bureau of the Census; (2002)

55. White MJ. Segregation and diversity: measures in population distribution. Popul Index. 1986; 52: 198-221.

56. Wilkes R, Iceland J. Hypersegregation in the twenty-first century. Demography. 2004; 41 (1): 23-36.

57. Denton NA, Massey DS. Patterns of neighborhood transition in a multi-ethnic world: U. S. metropolitan areas, 1970-1980. Demography. 1991; 28: 41-63.

58. Frey WH, Farley R. Asian, and Black segregation in U.S. metropolitan areas: are multiethnic metros different? Demography. 1996; 33: 35-50.

59. Lopez R. Income inequality and self-rated health in US metropolitan areas: a multi-level analysis. Soc Sci Med. 2004; 59(12): 2409-19.

60. Heron M, Hoyert DL, Murphy SL, Xu J, Kockanek KD, Tejada-Vera B. Deaths: final data for 2006. National Vital Statistics Reports. (2006); 57(14)

61. Centers for Disease Control and Prevention BRFSS. Obesity trends among US Adults Between 1985 and 2009. http://www.cdc.gov/obesity/data/trends.html\#State. Accessed August 24 